\title{
The University of Michigan Semester Research Program at CERN
}

\author{
Steven Goldfarb ${ }^{a, *}$ and Thomas Schwarz ${ }^{b}$ \\ ${ }^{a}$ School of Physics, University of Melbourne, \\ Parkville VIC 3010, Australia \\ ${ }^{b}$ Department of Physics, University of Michigan, \\ 500 S State St, Ann Arbor, MI 48109, USA \\ E-mail: steven.goldfarb@cern.ch, schwarzt@umich.edu
}

Since 2013, the University of Michigan has hosted a semester-long research program for undergraduate students at CERN. The students are selected from a diverse mix of small and large universities across the USA and are embedded in active experiments at the laboratory. The program is modelled on the successful Research Experience for Undergraduates (REU) program, which brings 15 students each year to participate in the CERN Summer Student Program, but addresses large demand for additional opportunities during the academic year. CERN mentors are selected due to their leadership skills and their ability to educate and inspire the students. Projects cover a wide range of activities from detector R\&D to software development, physics analysis and theoretical methodology, touching nearly all aspects of the research program at CERN.

Each semester, six students, selected from diverse backgrounds, spend three months working at the laboratory. They live in apartments in neighbouring St. Genis Pouilly, and enjoy periodic excursions to cultural centres around Europe. Funding, which covers travel, per diem and stipend, comes from the Richard Lounsbery Foundation, the University of Michigan Department of Physics, and most recently from the United States Mission in Geneva. We present the growing success of the program, its strategic interest to the US, and describe current efforts to expand and improve its diverse reach to all students across the country.

The Ninth Annual Conference on Large Hadron Collider Physics - LHCP2021

7-12 June 2021

Online

"Speaker

Copyright owned by the author(s) under the terms of the Creative Commons 


\section{Introduction}

Students of all professions can benefit from internships designed to develop their skills and provide them with exposure to current real-life applications with experts in their field. This is especially true for university-level students in the sciences considering careers in research. At this age, students might have obtained essential scientific knowledge from their coursework, but often still lack working environment experience, including complex research-related problemsolving and the rewarding challenges of working in diverse international research teams.

With this in mind, CERN founded a Summer Student program [1] in 1962, offering an opportunity for undergraduate students in the member states to come to Geneva to work with top researchers in physics, engineering and computing for 2-3 months between semesters. The program was instantly successful and has grown in size every summer, since. Typically, around 3000 students apply for entry to the program, which accepts around 280. In 1998, funding was secured through the National Science Foundation (NSF) [2] Research Experience for Undergraduates (REU) program [3] to include U.S. students. This program, administrated by the University of Michigan [4], brings 15 students, selected from across the U.S., to CERN for 9 weeks every summer.

The success of the U.S. CERN REU program is evident by its popularity (300 students apply for 15 places) and by the success rate of students who taken part in the program, as measured through surveys, fraction of students attending graduate studies, and the success of those students in their career path. Growing demand for the program by both students and mentors, as well as a desire by students to experience more in-depth research opportunities - in some cases to satisfy undergraduate research requirements - led the University of Michigan to consider the development of a nation-wide Semester Abroad program at CERN [5].

\section{The Program}

\subsection{Origins and Pilot}

A national semester program at CERN was first considered in 2008 as a means to address increasing demand from students to participate in research and from scientists at CERN to host research projects during the semester. Furthermore, it would be an opportunity to recruit students from underrepresented communities and to offer a more in-depth research experience than can be provided by the nine-week summer program. Such an opportunity is desired, and often required, as part of their undergraduate studies.

Following discussions and planning sessions with the NSF, U.S. Department of Energy [6], U.S. State Department [7], American Physical Society [8], leadership from the LHC experiments and others, the Richard Lounsbery Foundation [9] awarded the University of Michigan a grant to fund a pilot Research Semester program at CERN in Fall 2013 and Winter 2014. Prof. Jean Krisch and Prof. Thomas Schwarz (author) served as Principal Investigators (PIs) and Steven Goldfarb (author) served as on-site coordinator. Three students were selected to attend from mid-September to mid-December, 2013, and another six attended mid-January to mid-April, 2014. 
Evaluations and results of the pilot were impressive. Registration of the students as CERN Users provided them with access to the same scientific meetings, publications, colloquia and seminars as their collaboration members. The advantage of the 3-month semester over a 2month summer turned out to be important, as there is a significant learning curve occupying the first few weeks of the projects. The added month effectively doubled the effort the semester students were able to contribute, which was notable in the depth and complexity of their projects, and in the positive feedback given by the mentors.

It is important to note that no students lost time on their academic schedule. Several received credit from their home institutes for research carried out in the program. A few took online courses and had their exams proctored by the on-site coordinator at CERN. All of the students agreed that, even if they had to delay graduation, the value of the experience enhanced the value of their applications for postgraduate studies or research jobs following graduation.

\subsection{Fall 2014 - Winter 2019}

\subsubsection{Richard Lounsbery Foundation and U.S. State Department Grants}

The Richard Lounsbery Foundation awarded a grant for five students, each semester, from Fall 2014 to Winter 2017. Upon completion of the first grant and the clear establishment of the program's viability, a "Phase 2" extension was awarded to allow us to continue through Winter 2019, while preparing to seek a long-term funding solution.

For Winter 2018, representatives of the U.S. State Department from the U.S. Permanent Mission in Geneva [10] proposed funding students in a partnership designed to increase the participation of women and minority students in research. Two students were supported that semester and eight more students were supported in three subsequent semesters.

\subsubsection{Student Selection}

Students are recruited nationally and selected from a wide variety of colleges and universities. Efforts are made to achieve a balance between small and large schools, as well as between institutes already involved in CERN research and those that are not. Over the past five years, students were accepted from 33 different universities, providing them with the chance to meet and interact with others of a variety of social and cultural backgrounds. Approximately one-third of the 59 students were women and at least 11 came from under-represented groups in the field.

\subsubsection{Research Projects}

CERN experiments offer a wide variety of projects, from hardware construction to electronics $R \& D$, data acquisition, trigger development, data analysis, computing and software, etc. We make an effort to find challenging and fulfilling projects that are appropriate for the skills and interests of the students. Over the years, we have also identified mentors who are well-suited to oversee the work of the students in a pedagogical manner, promoting a sense of learning and accomplishment. The three-month duration of the program allows the students and mentors to establish meaningful relationships and to delve deep into the subject matter.

Three times during the semester, the students give presentations to each other about their projects. The on-site coordinator and program leads chair the presentations, and the students are encouraged to ask each other questions about their work. This provides a chance to check that 
the students understand the context of their work and that they have been given interesting and challenging problems. The final talks are longer and more formal. Students present as if they are at a conference and we record the talks for reference. Many of the students include links to these talks in their graduate school applications.

The program is a unique opportunity for the students to learn first-hand of the variety of CERN research. Beyond the LHC, students have been engaged in antimatter experiments, medical application research, scientific computing, and data preservation. Agenda of all presentations [11] include slides and videos of the talks. The projects were not only interesting and challenging to the students, but each left CERN knowing that she/he had made a significant contribution to the field of experimental particle physics at the premier high energy laboratory in the world, working alongside other scientists from around the planet.

\section{Program Evaluation}

In 2016, the University's Research Center for Group Dynamics at the Institute for Social Research reported findings on an independent survey carried out on the first two years of the semester research program. The executive summary from that survey states:

"Based on the findings, there is ample support for continuing the program. Its impact on students is demonstrable, positive, productive, and extensive. A semester-long experience does not have any of the negative impacts some have feared, such as interrupting normal progress toward a four-year timeline to get a degree. The knowledge and insights gained in that semester greatly increase students' understanding of what a career in physics might entail. This is a view shared by student participants and their advisors."

Following the Winter 2019 program, a survey was circulated to all past students [12]. We received 35 responses, all of whom expressed enthusiastic support for the program to continue. Below are some key statistics from the report, as well as some comments from the students.

- $94 \%$ claim participation in the program had a positive effect on their degree progress/plans;

- $74 \%$ intend to continue physical science studies at a postgraduate level;

- $100 \%$ feel the program made them more competitive as an applicant to future studies/jobs.

\section{Summary and Future Outlook}

Since 2013, the University of Michigan has administered an undergraduate research semester program at CERN, modelled after the NSF REU Summer Student program, but providing a longer and more in-depth research experience. By all measures, the program has exceeded its goals. Students not only develop skill sets and gain knowledge about cutting-edge research, but they learn how to work successfully in an international environment, expanding their social and cultural experience, and creating long-lasting ties with colleagues in their field.

The world-wide pandemic put the program on pause in March 2020, cutting short activities by a month. Nevertheless, the six students completed a significant amount of research and were able to report via videoconference in the Spring. The program is expected to resume in Winter 2022, depending on health considerations due to the pandemic. Additional resources are being sought to expand efforts to reach more students from under-represented communities. 


\section{References}

[1] CERN Summer Student program: https://home. cern/summer-student-programme.

[2] U.S. National Science Foundation: https : / / www . nsf . gov.

[3] NSF-funded Research Experience for Undergraduates program: https://www.nsf.gov/crssprgm/reu.

[4] UM CERN REU Summer Student program: http: / / um-cern-reu.org.

[5] UM CERN Research Semester program: http: //um-cern-semester.org.

[6] U.S. Department of Energy Office of Science: https://www.energy.gov/science/office-science.

[7] U.S. State Department: https://www.state.gov.

[8] APS Division of Particles and Fields (DPF): https: / / engage.aps.org/dpf/home.

[9] Richard Lounsbery Foundation: https : / /www.rlounsbery • org.

[10] United States Permanent Mission to the International Organisations in Geneva, Switzerland: https://geneva.usmission.gov.

[11] Student Presentations (REU and Semester): https: // indico. cern. ch/category/343.

[12] Survey of program alumni from 2019: http:// cern. ch/go/Mv7r. 